\title{
Molecular structure and biochemical properties of lignins in relation to possible self-organization of lignin networks
}

\author{
B. Monties
}

Laboratoire de Chimie Biologique, INRA (CBAI), Institut National Agronomique Paris-Grignon, Centre de Grignon, 78850 Thiverval-Grignon, France

\section{Introduction}

This review briefly recalls chemical data related to the variations in the molecular structure of lignin and mainly discusses the biochemical heterogeneity and occurrence of associations between lignins and other cell wall components. In an attempt to relate the formation of such lignin networks to possible functions of lignins, a new hypothesis on the self-organization properties of lignin is presented.

From a biochemical point of view, lignins are particularly complex polymers whose chemical structure changes within plant species, organs, tissues, cells and even cell fractions. Furthermore, from a physiological point of view, lignin biosynthesis is unusual in that the final polymerization step is only enzymatically initiated and is random chemically directed. Occurrence of such random synthesis raises the central question of the origin of the biological fitness of lignification to the life cycle of plants. This question is relevant not only for the formation of 'abnormal lignins' and 'lignin-like compounds' in reaction woods, and wounded and diseased tissues but also in the case of 'normal' lignin in wood xylem. Such random polymerization may also be relevant in relation to the evolution of the quality of the lignocellulosic products, such as during heartwood forma- tion, drying of logs and sawings, and hardboard and paper manufacture, as suggested, respectively, for example by Sarkanen (1971), Northcote (1972), Fry (1986), Back (1987), Jouin et al., (1988), and Horn and Setterholm (1988).

This review focuses thus on self-organization and recalls only briefly the chemical and biochemical properties of lignin in relation to other plant cell wall components. Due to edition constraints, only main relevant references are cited.

\section{Molecular structure of lignin}

In vitro model studies and in vivo experiments (Freudenberg and Neish, 1968; Higuchi, 1985) have shown that the general molecular structure of lignin can be explained by one-electron oxidation of cinnamyl alcohols followed by non-enzymatic polymerization of the corresponding mesomeric free radicals.

Fig. 1 shows the phenylpropane $\left(\mathrm{C}_{6}-\mathrm{C}_{3}\right)$ skeleton of the lignin monomers (M) and the structure of 4 of the most common linkages found in lignins. These structures have been established by in vitro peroxidase oxidation of mainly coniferyl alcohol ( $G$ = Fig. 1), followed by isolation of dimers (dilignols), oligomers (oli- 


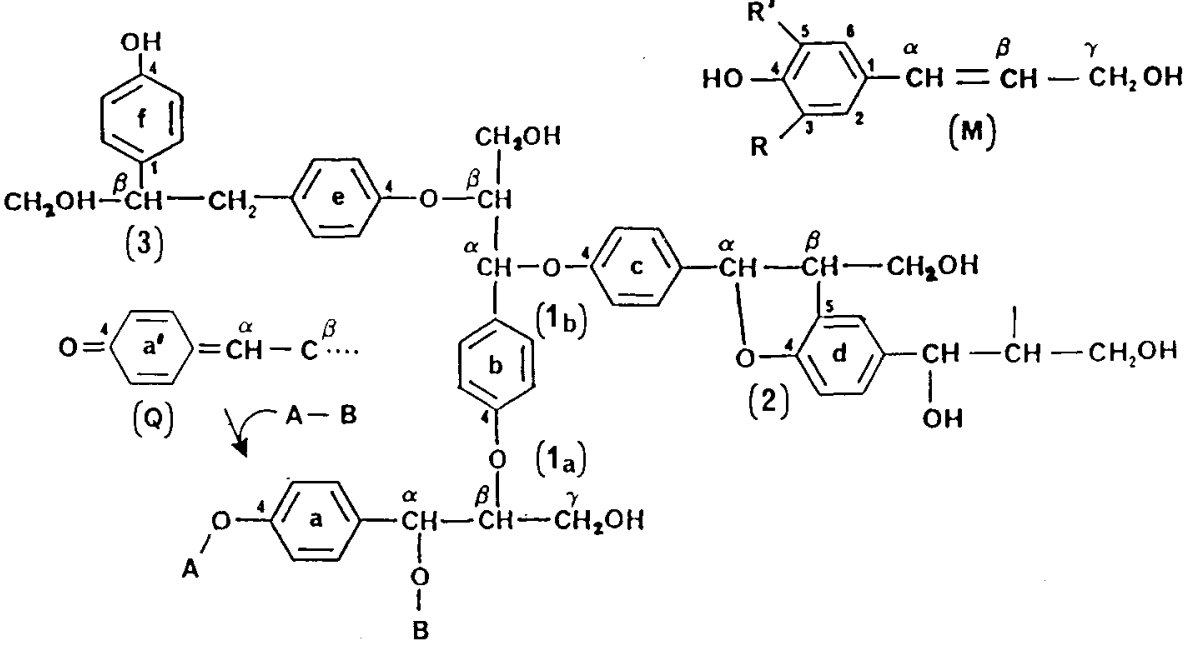

Fig. 1. Molecular structure of lignin monomers and of the more prominent intermonomeric linkages in lignins. Three main types of monomers $(M)$ can be polymerized: $p$-hydroxyphenyl alcohol $H\left(R=R^{\prime}=H\right)$; coniferyl alcohol $G(R=$ $\left.\mathrm{H}, \mathrm{R}^{\prime}=\mathrm{OCH}_{3}\right)$ and sinapyl alcohol $\mathrm{S}\left(\mathrm{R}=\mathrm{R}^{\prime}=\mathrm{OCH}_{3}\right)$. Formation of the terminal $\mathrm{A}, \mathrm{B}$-substituted monomeric unit (a) occurs by addition of $\mathrm{A}-\mathrm{B}$ to the corresponding terminal monomeric unit (a'), with a $p$-methylene quinone structure (Q) as discussed under Biochemical properties.

golignols) and dehydropolymers (DHP model). Model polymerization studies have also shown that the relative frequency of these intermonomeric linkages and, thus, the corresponding macromolecular structure of DHP changes according to polymerization conditions (Sarkanen, 1971), such as, the concentrations and the rate of addition of the reagents, the polarity of the medium or solvents, the electronic and steric effects of the substituents in the aromatic cycle, according to the various substitution patterns of the lignin monomeric units: $\mathrm{H}, \mathrm{G}, \mathrm{S}$ (Table I).

Formation of para- and ortho-quinone methide has also been suggested during the dimerization of mesomeric oligolignols or monomeric units and during chemical oxidation of simple phenolic model compounds (Harkin, 1966). Intermediate oligolignol-p-quinone methides are implicated in the formation of lignin networks. According to in vitro experiments, such structures are involved in the growth of the lignin polymer through copolymerization, but also through heteropolymerization with other macromolecules, such as polysaccharides (Sarkanen, 1971; Higuchi, 1985). Fig. 1 shows the addition reaction between a compound $\mathrm{A}-\mathrm{B}$ and a terminal $p$ methylene quinone unit ( $a$ ': Fig. 1). Addition of $A-B$ led to the formation of the corresponding $A, B-(a)$ substituted hexalignol (a-f: Fig. 1). Depending upon the structure of $A-B$ and when $A$ is hydrogen, the aromatic character of the a-monomeric unit is recovered with reformation of a phenolic group. This phenolic unit may further polymerize, leading to a trisubstituted monomeric unit or 'branch point' of the lignin network (Pla and Yan, 1984). Such a reticulation process with reformation of a phenolic group could be a significant self-organization property of lignin (see below). Depending upon the A-B structure, the addition reaction shown in Fig. 1 may also be important and thus explain certain macromolecular regulari- 
Table I. Effect of the condition of polymerization and of the structure of the monomeric units on the frequency of the intermonomeric linkages in model dehydrogenation.

\begin{tabular}{|c|c|c|c|c|}
\hline \multirow{2}{*}{$\begin{array}{l}\text { Solvent conc.a } \\
\text { (oxidant) }\end{array}$} & \multirow{2}{*}{$\begin{array}{l}\text { Monomer } \\
\text { (structure) }\end{array}$} & \multicolumn{3}{|c|}{ Frequency of linkages b (\%) } \\
\hline & & $\beta$-aryl ether & coumarane & resinol \\
\hline $\begin{array}{l}\text { Water } \\
\left(\mathrm{H}_{2} \mathrm{O}_{2} \text {, peroxidase }\right) \\
\text { Acetone water } \\
\left(\mathrm{FeCl}_{3}\right)\end{array}$ & $\begin{array}{l}\text { coniferyl } \\
\text { sinapyl } \\
\text { coniferyl } \\
\text { sinapyl }\end{array}$ & $\begin{array}{r}19 \\
9 \\
27 \\
27\end{array}$ & $\begin{array}{l}54 \\
\mathrm{nf} \\
27 \\
\mathrm{nf}\end{array}$ & $\begin{array}{l}27 \\
91 \\
46 \\
73\end{array}$ \\
\hline
\end{tabular}

a Concentration and other conditions of dehydrogenation were different (Tanahashi et al., 1976).

b $\beta$-Aryl ether and coumarane linkages shown in Fig. 1, respectively $1_{a}$ and 2; resinol linkage, in which a $\beta-\beta$ carbon-carbon bond occurs between 2 propane chains is mainly obtained during in vitro model polymerization but occurs less frequently in vivo, as in lignin structure (Fig. 1). nf: coumarane formation is inhibited by substitution on carbon 5 in the case of sinapyl alcohol.

ties in lignin structure. As early as in 1968 , Freudenberg and Neish stressed that "the sequence of the individual (monomeric) units in lignin is fortuitous, for they are not moulded like proteins on a template. This does not exclude the occurrence of a certain regularity in the distribution of weak and strong bonds between the units. As a rough estimate, 7 to 9 weak bonds are randomly distributed among 100 units, 'gluing' together more resistant clusters, of an average, 14 units." Such 'clusters' or 'primary chains' of about 18 strongly linked monomeric units have been reported after delignification experiments by Bolker and Brener (1971) and by Yan et al. (1984). According to these authors, the weak-bonds suggested by Freudenberg and Neish are mainly $\alpha$-aryl ether linkages, respectively, intermolecular $\left(\mathrm{C}_{\alpha}-\mathrm{O}-\mathrm{B}\right.$ bond in a-unit: Fig. 1$)$ and intramolecular $\left(\mathrm{C}_{\alpha}-\mathrm{O}-4\right.$ bond in b-unit: Fig. 1). Confirming the importance of addition reactions with $p$-methylene quinone, such a weak $\alpha$-aryl ether bond may correspond to a $\mathrm{C}_{\alpha}-\mathrm{O}-\mathrm{B}$ linkage $(\mathrm{a}=\mathrm{Fig} .1$ ) where $\mathrm{B}$ is a phenoxy substituent corresponding to the addition of a BA phenolic terminal monomeric unit. Summarizing the most characteristic chemical properties, lignin does not appear to be a defined chemical compound but a group of high molecular weight polymers whose random structure, which is related to their chemically driven polymerization, does not exclude the appearance of certain regularities in the 3 dimensional rietwork.

\section{Biochemical properties}

Biochemical heterogeneity or inhomogeneity (Monties, 1985) is the second main feature of lignin. Characteristic variations in lignin structure and monomeric composition have indeed been found and confirmed between plant species (Logan and Thomas, 1985), between plant organs and tissues grown either in vitro or in vivo and also between cell wall fractions (Hoffman et al., 1985; Sorvari et al., 1986; Saka etal., 1988; Eriksson et al., 1988). In agreement with these data, which cannot be discussed here in detail, heterogeneity in lignin formation and molecular structure, has been demonstrated in the case of gymnosperms (Terashima and Fukushi$\mathrm{ma}, 1988$ ) and in the case of angiosperms (Higuchi, 1985; Monties, 1985; Lapierre, 1986; Tollier et al., 1988; Terashima and Fukushima, 1988). From a biochemical point of view, lignin thus appears to be non-random heterogeneous copolymers enriched by either non-methoxylated ( $p$ hydroxyphenyl $=H$ ), monomethoxylated (guaiacyl = G) and dimethoxylated (syringyl = S) monomeric units (Fig. 1). These copolymers are unequally distributed amongst celis and subcellular layers, in 
tissues according to patterns changing with species. The biosynthesis of the precursors and the regulation of lignification most likely occurs within individual cells and variations are observed according to the type and the age of cells (Wardrop, 1976), as in the case of secondary metabolism (Terashima and Fukushima, 1988).

\section{Molecular associations and cell wall lignification}

Formation of molecular associations with other cell wall components is the third main feature of lignins. Indirect evidence of the occurrence of such heteropolymers, mainly based on extractability or liquid chromatographic experiments, has been reported in the case of polysaccharides, phenolic acids and proteins, tannins and some other simple compounds. The types of chemical bonds involved in these associations have been established only for polysaccharides, phenolic acids and proteins, mainly based on model experiments of addition to $p$-methylenequinone discussed previously.

The most frequently suggested types of lignin-carbohydrate complex (LCC) linkages are a benzyl ester bond with the $\mathrm{C}_{6}$ carboxyl group of uronic acids, a benzyl ether bond with the hydroxyl of the primary alcohol of hexose or pentose, a glycosidic bond with either the $\mathrm{C}_{4}$-phenolic hydroxyl or the $\mathrm{C}_{\gamma}$-primary alcohol of phenylpropane units ( $M=$ Fig. 1). The synthesis of LCC model compounds, their reactivity and their chemical or enzymatic stability have been compared to those of wood LCC (Higuchi, 1983; Minor, 1982; Enoki et al., 1983). Recently, using a selective depolymerization procedure, Takahashi and Koshijima (1988) have concluded that xylose participates in lignin-carbohydrate linkages through benzyl ether bonds in LCC from angiosperm (Fagus sp.) and gymnosperm (Pinus sp.) woods. Macromolecular differences were reported by these authors: in Fagus, the lignin moiety of LCC would consist of a small number of extremely large molecular fractions, while pine would have relatively smaller and more numerous fractions, confirming the hypothesis of biochemical heterogeneity of lignins.

Phenolic acids are known to be bound to lignin, especially in the cases of monocotyledons (grasses and bamboos) and Salicaceae (poplars). Ester bonds of phenolic acids to $\mathrm{C}_{\alpha^{-}}$and $\mathrm{C}_{\gamma^{-}}$-hydroxyls of monomeric propane chains (Fig. 1), $\mathrm{C}_{5^{-}}$ carbon-carbon bonds and ether bonds at $\mathrm{C}_{4}$-phenolic oxygen of aromatic cycles (Fig. 1) have been reported in the cases of model DHP (Higuchi, 1980) and gramineae lignins from wheat (Scalbert et al., 1985) and reed, Arundo sp. (Tai et al., 1987). Ether linkages of phenolic acids have been tentatively implicated in the characteristic alkali solubility of grass lignins; however, free phenolic hydroxyl groups would also participate in this solubility (Lapierre et al., 1989).

Lignin-protein complexes in the cell wall of pine (Pinus sp.) callus culture have been reported: covalent bonds, formed preferentially with hydroxyproline, have been suggested on the basis of selective extraction experiments and of the reactivity of model DHPs containing hydroxyproline, which were more stable to acid hydrolysis than carbohydrate-DHP complexes (Whitmore, 1982). Chemical bonds between lignin and protein have also been recently indicated during the differentiation of xylem in birch wood, Betula sp. (Eom et al., 1987). A gradual decrease in phenolic hydroxyl group content and changes in molecular weight distribution during the lignification have also been shown by these authors. These variations were explained in terms of changes in lignin structure in relation to variations in concentrations of available monomers and effects of the conditions of polymerization as discussed above.

Possible associations with other phenolics, such as condensed and hydrolyzable tannins have also been suggested in rela- 
tion to the difficulties in completely removing tannins, after solvent and mild chemical extractions of woods and, also in relation to coprecipitation, such as sulfuric acid-insoluble lignin fractions. Mechanisms of random, i.e., chemically-driven polymerization of tannins with cell wall components, have been discussed recently (Haslam and Lilley, 1985; Jouin et al., 1987). However, no evidence of chemical bonds between tannins and lignins was given.

\section{Network formation and self-organiza- tion properties}

Formation of molecular associations between lignins and cell wall components sheds light on the importance of the phenolic group's reactivity, such as the addition to methylene quinone with phenolic group reformation (Fig. 1), in the reticulation of the plant cell wall. Such reactivity is not unique, since phenol dimerization, by formation of diphenyl and of diarylether bonds, has also been reported for tyrosine during cell wall cross-linking processes (Fry, 1986). Recently, similar reactions have also been suggested for tyramine in the phenolic fraction associated with suberin (Borg-Olivier and Monties, 1989). As very clearly stressed by Northcote as early as 1972 , with reference to synthetic fibrous composite, the formation of such cross-linked phenolic polymers may be significant in regard to the structure and functions of plant cell walls. Reticulation may be of importance in durability and mechanical properties, as recently discussed in the case of cell wall proteins by Cassab and Warner (1988). Furthermore, in the case of lignins, this cross-linking phenomenon may be of much more general interest. For example, the formation of chemical bonds in the residual lignin network of thermomechanical pulps has been implicated in the autocross-linking of these cellulosic fibers during the production of paper and hardboard in the so called 'press-drying' process (Back, 1987; Horn and Setterholm, 1988).

In order to try to understand the general formation of phenolic networks by nonenzymatic polymerization processes, selforganizing properties of lignin can be suggested. The self-organization concept comes from the general theory of systems. Self-organization accounts for the manner in which complex systems adapt to and increase their organization under the stimulation of random environmental factors. This theory has been applied extensively to the growth of organisms and transmission of information (Atlan, 1972). Selforganization also seems relevant in the case of lignin, since lignin is a non-enzymatic polymerized macromolecule, its structure changes as a function of random external environmental factors, it rearranges during maturation, ageing or technological transformations and, finally, these changes provide a better fitness of cell wall functions, such as resistance against biotic and abiotic factors.

According to Atlan (1974), a self-organizing systern is a complex system in which changes in organization occur with increasing efficiency in spite of the fact that they are induced by random environmental factors; changes are not directed by a template. Self-organization capacity can be expressed as a function of 2 main parameters: redundancy and reliability. When the organization is defined as 'variety and inhomogeneity' of the system, redundancy is viewed as 'regularity or order as repetitive order' and reliability expresses the system's 'inertia opposed to random perturbation'. According to these definitions, the information content, i.e., the organization of a system, can be expressed as a function of redundancy and of time (see Annex). Evolution of the organization as a function of time can thus be calculated showing different types of organization.

Thus, a self-organizing system is characterized by a defined maximum organization resulting from an initial increase in inhomogeneity associated with a contin- 
uous decrease in redundancy under the effect of random environmental factors. At the other extreme, a non-self-organizing system shows a continuous decrease of organization, mainly due to a low initial redundancy. Furthermore, intermediate cases have also been described by Atlan (1972, 1974) corresponding to relatively very high or very low reliability and leading, respectively, to a very long or a very short duration of the initial phase of increase in organization. According to Atlan (1974), crystals can be viewed as a nonself-organizing system because of low initial reliability in spite of their large redundancy. At the other extreme, less repetitive and more flexible structures, such as macromolecular systems, can be selforganizing.

In agreement with this model, it is suggested that lignin networks be considered as self-organizing systems, thus explaining the formation of molecular complexes by auto- and heteropolymerization in plant cell walls with an increase of lignin functional properties.

The high frequency of relatively labile intermonomeric linkages, such as $\beta$ - and mainly $\alpha$-ether bonds, and also of easily activated groups, such as free phenolic terminal units (Fig. 1), may allow rearrangement reactions and, thus, easy evolution of the system as a function of random environmental factors. Occurrence of chemical and biochemical regularities, previously discussed, may, in addition, provide enough initial redundancy. Finally, a high reliability, i.e., inertia to perturbation, may result from the ability to reform phenolic groups after, for example, an addition reaction as shown in Fig. 1, but also from the release of reactive phenolic and/or benzylic groups after $\beta$ - and mainly $\alpha$-ether cleavage.

In conclusion, even when lignin formation appears as an enzyme-initiated and chemically driven process, structural studies have provided evidence of regularities in chemical and biochemical properties in lignin networks. Such regularities may allow self-organizing properties of lignin macromolecules, explaining their functional fitness and the biological significance of the 'random process' of lignification. However, until now, this theory suffers from 2 main drawbacks: a lack of quantitative evaluation and a definite account of the phylogenic and ontogenic significance of the substitution pattern of the lignin monomeric units.

\section{Acknowledgments}

Thanks are due to Drs. Catherine Lapierre, C. Costes and E. Odier for critical assessment of the manuscript and to Kate Hervé du Penhoat for linguistic revisions.

\section{References}

Atlan H. (1972) In: L'organisation biologique et la théorie de linformation. Hermann, Paris, pp. 229

Atlan $H$. (1974) On a formal definition of organization. J. Theor. Biol. 45, 295-304

Back E.I. (1987) The bonding mechanism in hardboard manufacture. Holzforschung 41, 247-258

Bolker H.I. \& Brener H.S. (1971) Polymeric structure of spruce lignin. Science 170, 173-176

Borg-Olivier O. \& Monties B. (1989) Characterization of lignins, phenolic acids and tyramine in the suberized tissues of natural and woundinduced potatoe periderm. C.R. Acad. Sci. Ser. III $308,141-147$

Cassab G.I. \& Varner J.E. (1988) Cell wall proteins. Annu. Rev. Plant Physiol. 39, 321-353

Enoki A., Yaku F. \& Koshijima T. (1983) Synthesis of LCC model compounds and their chemical and enzymatic stabilities. Holzforschung 37 , 135-141

Eom T.J., Meshitsuka G., Ishizu A. \& Nakano T. (1987) Chemical characteristics of lignin in differentiating xylem of a hardwood III. Mokuzai Gakkaishi 33, 716-723

Eriksson I., Lindbrandt $O$. \& Westermark U. (1988) Lignin distribution in birch (Betula verucosa) as determined by mercurization with SEM- and TEM-EDXA. Wood Sci. Technol. 22, 251-257 
Freudenberg K. \& Neish A.C. (1968) In: Constitution and Biosynthesis of Lignin. Springer-Verlag, Berlin, pp. 129

Fry S.C. (1986) Cross-linking of matrix polymers in the growing cell walls of angiosperms. Annu. Rev. Plant Physiol. 37, 165-186

Harkin J.M. (1966) O-Quinonemethide as tentative structural elements in lignin. Adv. Chem. Ser. 59, 65-75

Haslam E. \& Lilley T.H. (1985) New polyphenols from old tannins. In: The Biochemistry of Plant Phenolics. Annu. Proc. Phytochem. Soc. Eur. (van Sumere C.F. \& Lea P.J., eds.), 25, 237-256

Higuchi T. (1983) Biochemistry of lignification. Wood Res. 66, 1-16

Higuchi T. (1985) Biosynthesis of lignin. In: Biosynthesis and Biodegradation of Wood Components. (Higuchi T., ed), Academic Press, Orlando, pp. 141-160

Hoffman A. Sr., Miller R.A. \& Pengelly W.L. (1985) Characterizations of polyphenols in cell walls of cultured Populus trichocarpa tissues. Phytochemistry 24, 2685-2687

Horn R.A. \& Setterholm V. (1988) Press drying: a way to use hardwood CTMP for high-strength paperboard. TAPPI 71, 143-146

Jouin D., Tollier M.T. \& Monties B. (1988) Lignification of oak wood: lignin determinations in sapwood and heartwood. Cell. Chem. Technol. 22, 231-243

Lapierre C. (1986) Hétérogénéité des lignines de peuplier: mise en évidence systématique. Ph.D. Thesis, Université d'Orsay, France

Lapierre C., Jouin D. \& Monties B. (1989) On the molecular origin of the alkali solubility of gramineae lignins. Phytochemistry 28, 14011403

Logan K.J. \& Thomas B.A. (1985) Distribution of lignin derivatives in plants. New Phytol. 99, 571-585

Minor J.L. (1982) Chemical linkage of pine polysaccharide to lignin. J. Wood Chem. Technol. 2, 1-16

Monties B. (1985) Recent advances in lignin inhomogeneity. In: The Biochemistry of Plant Phenolics. Annu. Proc. Phytochem. Soc. Eur. (van Sumere C.F. \& Lea P.J., eds.), 25, 161-181

Northcote D.H. (1972) Chemistry of plant cell wall. Annu. Rev. Plant Physiol. 23, 113-132

Pla F. \& Yan Y.F. (1984) Branching and functionality of lignin molecules. J. Wood Chem. Technol. 4, 285-299
Saka S., Hosoya S. \& Goring D.A.I. (1988) A comparison of bromination of syringyl and guaiacyl type lignins. Holzforschung 42, 79-83

Sarkanen K.V. (1971) Precursors and their polymerization. In: Lignins: Occurrence, Formation, Structure and Reactions. (Sarkanen K.V. \& Ludwig C.H., eds.), Wiley Interscience, New York, pp. 138-156

Scalbert A., Monties B., Lalemand J.Y., Guittet E. \& Rolando C. (1985) Ether linkage between phenolic acids and lignin fractions from wheat straw. Phytochemistry 24, 1359-1362

Sorvari J., Sjostrom E., Klemola A. \& Laine J.E. (1986) Chemical characterization of wood constituents especially lignin in fractions separated from middle lamella and secondary wall of Norway spruce (Picea abies). Wood Sci. Technol. 20, 35-51

Tai D., Cho W. \& Ji W. (1987) Studies on Arundo donax lignins. Proc. Fourth int. Symp. Wood Pulping Chem. 2, C.T.P., Grenoble, pp. 13-17

Takahashi \& Koshijima (1988) Molecular properties of lignin--carbohydrate complexes from beech (Fagus crenata) and pine (Pinus densiflora) woods. Wood Sci. Technol. 22, 177-189

Tanahashi M., Takeuchi H. \& Higuchi T. (1976) Dehydrogenative polymerization of 3,5-disubstituted p-coumaryl alcohols. Wood Res. 61, 4453

Terashima N. \& Fukushima K. (1988) Heterogeneity in formation of lignin: autoradiographic study of formation of guaiacyl and syringyl lignin in Mangnolia kobus D.C. Holzforschung 40 suppl., 101-105

Tollier M.T., Monties B. \& Lapierre C. (1988) Heterogeneity in angiosperm lignins. Holzforschung, 40 suppl., 75-79

Wardrop A.B. (1976) Lignification in plant cell wall. Appl. Polym. Symp. 28, 1041-1063

Whitmore F.A. (1982) Lignin-protein complex in cell walls of Pinus elliottii: amino acid constituents. Phytochemistry 21, 315-318

Yan J.F., Pla F., Kondo R., Dolk M. \& McCarthy J.L. (1984) Lignin: 21: depolymerization by bond cleavage reactions and degelation. Macromolecules: 17, 2137-2142

\section{Annex}

According to Atlan's proposal, organization should correspond to an optimum compromise between maximum informa- 
tion content $\left(H_{\max }\right)$ and redundancy $(R)$ tion effects due to random perturbations. both considered as a function of time. The second term, however, is positive Starting from Shannon's definition:

$H=H_{\max }(1-R)$

and differentiating $H$ versus time, with the assumption that time means accumulated random perturbation from the environment, one gets:

$\mathrm{d} H / \mathrm{d} t=(1-R)\left(\mathrm{d} H_{\max } / \mathrm{d} t\right)+H_{\max }(-\mathrm{d} R / \mathrm{d} t)$

As perturbations decrease both $H_{\max }$ and $R$, the first term on the right side of eqn. 1 is negative and thus shows disorganizaexplaining a possible increase in organization and thus self-organization under the effect of random perturbations. A selforganizing system appears, thus, to be redundant enough to sustain a continuous process of disorganization, first term, constantly associated with reorganization and increased efficiency of the system due to its reliability, i.e., its inertia opposed to random perturbations, the second term of eqn. 1. 